\title{
The current burden of allergic rhinitis amongst primary care practitioners and its impact on patient management
}

\author{
Paul Van Cauw enberge ${ }^{\mathrm{a}},{ }^{*}$ Helen Van Hoecke ${ }^{\mathrm{at}}$, Peter Kardos ${ }^{\mathrm{b}}$, David Price ${ }^{\mathrm{c}}$, Susan Waserman ${ }^{\mathrm{d}}$ \\ a Department of Otorhinolaryngology, Ghent University Hospital, Ghent, Belgium ('shared first authorship) \\ ${ }^{\mathrm{b}}$ Allergy, Respiratory and Sleep Medicine Unit \& Group Practice, Red Cross Maingau Hospital, Frankfurt, Germany \\ ' GPIAG Professor of Primary Care Respiratory M edicine, University of A berdeen, Scotland, UK \\ ${ }^{d}$ Department of Clinical Immunology and Allergy, M cM aster University, Ontario, Canada
}

Received 17th December 2007; revised version received 13th May 2008; accepted 27th May 2008; online 12 th July 2008

\begin{abstract}
Aims: To investigate the burden of allergic rhinitis (AR) amongst primary care practitioners (PCPs), the impact of AR on PCPs' professional lives, and the effect on their management of AR patients of PCPs' personal experience of AR.

Methods: An online questionnaire was completed by 1201 PCPs (50\% AR sufferers) from eight countries.

Results: $21 \%$ of PCPs reported very well controlled symptoms and $66 \%$ quite good control. Six hours work per week, on average, was missed by PCPs whose AR symptoms resulted in absence. AR symptoms affected concentration, stress level, mood, time spent with patients, physical contact with patients, and patient throughput. PCPS with AR reported a significantly higher proportion of AR patients in their practice and gave a significantly higher ranking to specific treatment requests and emotional well-being, and gave a significantly lower ranking to preventing comorbidity development and providing a treatment most likely to result in high patient compliance.

Discussion: This is the first study demonstrating the impact of AR on PCPs showing association with lost productivity, absenteeism and reduction in professional performance. Personal experience of AR significantly influences PCPs' management of AR and may improve their AR diagnostic ability.

(C) 2009 General Practice Airways Group. All rights reserved.

P Van Cauwenberge, et al. Prim Care Resp J 2009; 18(1): 27-33.

doi:10.3132/pcrj.2008.00042
\end{abstract}

Keyw ords allergic rhinitis, primary care practitioners, questionnaire, morbidity, patient management

The full version of this paper, with online Appendices $A$

and $B$, is available online at www.thepcrj.org

\section{Introduction}

Allergic rhinitis (AR) is a common, symptomatic disorder induced by allergen exposure and subsequent IgE-mediated inflammation of the membranes lining the nose. ${ }^{1}$ In 2001, the Allergic Rhinitis and its Impact on Asthma (ARIA) Workshop Group, in collaboration with the World Health Organisation (WHO), introduced a new classification which subdivided AR as either intermittent or persistent, and either mild or moderate-severe, depending on the duration, severity, and impact of symptoms on quality of life (see Table 1). ${ }^{1}$

Although many sufferers self-treat and seek medical help only when their symptoms become intolerable, ${ }^{2}$ AR remains amongst the top ten reasons for visits to primary care clinics. ${ }^{3}$ Updated management guidelines have recently been published by the International Primary Care Respiratory Group (IPCRG). ${ }^{4}$ Several studies have examined the detrimental effects of AR on the working lives of sufferers amongst the general population, ${ }^{5-}$ ${ }^{9}$ but to date there has been no published research investigating the effects of AR symptoms on the professional lives of primary care physicians (PCPs) themselves.

Therefore, the aim of this study was to investigate whether suffering from AR has a negative impact on the professional lives and performance of PCPS, and to assess whether or not personal experience of AR influences their management of patients with the disease.

\footnotetext{
* Corresponding author: Dr Helen Van Hoecke, De Pintelaan 185, Ghent 9000, Belgium.

Tel: +3293324446 Fax: +3293324993 E-mail: helen.vanhoecke@ugent.be
} 


\begin{tabular}{|c|c|}
\hline Intermittent & $\begin{array}{l}\text { Symptoms are present: } \\
\text { - } \quad \text { Less than } 4 \text { days a week } \\
\text { - } \quad \text { Or for less than } 4 \text { weeks }\end{array}$ \\
\hline Persistent & $\begin{array}{l}\text { Symptoms are present: } \\
\text { - } \quad \text { More than } 4 \text { days a week } \\
\text { - } \quad \text { And for more than } 4 \text { weeks }\end{array}$ \\
\hline Mild & $\begin{array}{l}\text { None of the following items are present } \\
\text { - } \quad \text { Sleep disturbance } \\
\text { Impairment of daily activities, leisure } \\
\text { - } \quad \text { Implor sport } \\
\text { - Troublesome symptoms }\end{array}$ \\
\hline Moderate-severe & $\begin{array}{l}\text { One or more of the following items are present: } \\
\text { - } \quad \text { Sleep disturbance } \\
\text { Impairment of daily activities, leisure } \\
\text { and/or sport } \\
\text { - } \quad \text { Impairment of school or work } \\
\text { - Troublesome symptoms }\end{array}$ \\
\hline
\end{tabular}

\section{Materials and methods Design of the study}

The questionnaire, which was quantitative and devised for online completion, was derived from existing and validated questionnaires, ${ }^{10}$ with the addition of a number of novel questions covering demographic details, PCPs' personal experience of $A R$, self-treatment, impact of $A R$ on their working lives, and their management of patients with $A R$. In order to test the viability and technical functionality of the electronic questionnaire, 10 pilot online interviews were conducted amongst PCPs who qualified according to the eligibility criteria for the main study as described below. Amendment of the initial questionnaire resulted in a final version (see Appendix A at www.thepcri.org) which consisted of 21 closed questions. PCPs were advised that the questionnaire would take approximately 15 minutes to complete, that it would be available for completion for a period of four weeks, and that those who participated would receive a small cash payment for completing the questionnaire. The questionnaire was translated from English into five other languages (French, German, Italian, Portuguese and Spanish) but there was no allowance made for regional variations in English or French.

\section{Recruitment and eligibility of PCPs}

In order to ensure sufficiently high numbers of participants from eight countries, PCPs were recruited from a panel of healthcare professionals, of all specialties, who were prepared to take part in such studies. However, they were not preselected for health-related or other reasons. The panel was managed by an independent group specialising in healthcare recruitment. All PCPs on the panel received a personal invitation and were eligible for inclusion if at the time of participation they were aged 25-65 years, were qualified and currently practising, had been in practice for 2-30 years, and had not participated in research on allergies of any kind in the previous three months.

In order to be able to compare PCPs with and without AR, $50 \%$ of the total sample from each country had to be $A R$ sufferers and $50 \%$ AR non-sufferers. AR status was selfdiagnosed by the PCPs as part of the screening criteria according to a simplification of the ARIA guidelines, outlined in the questionnaire as:

- Intermittent AR: the presence of symptoms for $\leq 4$ weeks per year

- Persistent AR: the presence of symptoms for $\geq 4$ w weeks per year.

Self diagnosis by PCPs of AR for the purposes of this study reflects normal clinical practice for such conditions.

The total sample was designed to include approximately 1200 PCPs recruited from eight countries (Australia, Brazil, Canada, France, Germany, Italy, Spain and the UK), which were chosen to enable trends to be identified and explored from a global representation of markets.

\section{Statistical analysis}

Data were entered into QPSMR software (Wallingford, UK) and tabulated for analysis. Statistical differences were assessed for means using t-testing of two independent sample means. This method was selected since use of the ttest is standard practice in market research when analysing rating scales. Although the data are not strictly of interval form and often not normally distributed, the t-test was considered robust enough to allow for this. For proportions, z-testing of two independent sample proportions was used. Statistical significance was recognised at the $5 \%$ level in all cases. For Question 11 of the questionnaire (impact of $A R$ symptoms on ability to perform daily tasks), the following statistical method was used: PCPs rated only the symptoms they personally experienced for their impact on ability to perform daily tasks; as the number of symptoms varied for each individual, each symptom was allocated a new rank value on a comparable scale ranging from 1 to 3; finally, the impact of each symptom was determined from its prevalence in the top, middle or bottom third of individual rankings, with symptoms appearing more frequently in the top third than bottom third considered as being more impactful on the population as a whole.

\section{Results}

\section{Demographics of the study population}

Of the 2817 PCPs assessed for eligibility, 894 were unable or unwilling to complete the study. A further 343 PCPs did not meet the eligibility criteria. A final 379 PCPs were excluded 
Table 2. Symptoms reported by PCPs with AR (when not taking medication)

\begin{tabular}{lc} 
Symptoms suffered & $\begin{array}{c}\text { Percentage of PCP AR } \\
\text { sufferers (n=600) }\end{array}$ \\
\hline Sneezing & $72 \%$ \\
Runny nose & $66 \%$ \\
Blocked nose & $59 \%$ \\
Itchy nose & $58 \%$ \\
Itchy/red eyes & $45 \%$ \\
Watery eyes & $39 \%$ \\
Post nasal drip & $33 \%$ \\
Itchy palate & $29 \%$ \\
Cough & $26 \%$ \\
Headache & $23 \%$ \\
Snoring & $22 \%$ \\
Sinus pressure & $21 \%$ \\
Waking at night & $19 \%$ \\
Sore throat & $17 \%$ \\
Wheezing & $15 \%$
\end{tabular}

because the pre-specified populations with or without AR had been achieved by the time of their recruitment.

The total study population therefore consisted of 1201 PCPs from eight countries - Australia, Brazil, Canada, France, Germany, Italy, Spain and the UK - with 150 PCPs from each with the exception of Brazil where the online program closed when one extra PCP above the required 150 had completed the questionnaire. The mean age of the PCPs was 47 years, with $7 \%$ falling in the 25 to 34 years age range, 29\% aged 35 to 44 years, $46 \%$ aged 45 to 54 years and $18 \%$ aged 55 to 65 years. Seventy-three per cent were male and $27 \%$ female. Of the 600 PCPs self-diagnosed with $A R, 71 \%$ had intermittent AR and $25 \%$ had persistent AR. A total of 28 PCPs $(16 \%)$ reported having both intermittent $A R$ and persistent AR.

\section{Perceived symptom control amongst PCPs with AR}

Nasal symptoms such as sneezing and runny, blocked or itchy nose, were the most commonly reported by PCPs (see Table 2 ). Both nasal and ocular symptoms were reported by $55 \%$ $(n=326)$ of the PCPs, $41 \%(n=248)$ had nasal symptoms only, and $1 \%(n=5)$ ocular symptoms only.

Oral antihistamines were the most frequently used treatment $(66 \%)$, followed by intranasal glucocorticoids $(44 \%)$, environmental control measures $(29 \%)$ and intranasal decongestants (26\%) (see Table 3). PCPs using oral antihistamines were significantly more likely to report that their AR symptoms were quite or very well controlled than quite or very poorly controlled $(p=0.037)$. PCPs using environmental control measures or intranasal decongestants were significantly less likely to report that their symptoms were quite or very well controlled than quite or very poorly controlled $(p=0.013$ for environment control measures; $p<0.0001$ for intranasal decongestants). Overall, $21 \%$ of PCPs considered their symptoms to be very well controlled and $66 \%$ reported quite good control. No significant difference was demonstrated between PCPs with nasal and PCPs with ocular symptoms in the perceptions of the level of their symptom control. The results obtained for symptom control were very similar between countries.

\section{Effects of AR symptoms on PCPs' professional lives}

An average of six hours work missed per week was reported by the $27 \%$ of PCPs who said that their AR symptoms resulted in absence from work, late arrival or early departure. PCPs reporting very good symptom control were significantly more likely to report no time lost from work compared with those reporting very poor control (85\% versus $50 \%$; $p=0.010)$. The results indicated that, compared to those who were not self-employed, self-employed PCPs were significantly less likely to miss work $(p=0.022)$ and also missed significantly fewer hours of work a week ( 0.8 hours versus 1.8 hours; $p=0.001$ ) due to AR symptoms, although this was independent of the level of symptom control. Compared with

Table 3. Treatment use and symptom control reported by PCPs with AR

\begin{tabular}{|c|c|c|c|c|c|}
\hline \multirow[b]{2}{*}{ Treatment type } & \multirow[b]{2}{*}{$\begin{array}{l}\text { All PCPs } \\
(n=600)\end{array}$} & \multicolumn{4}{|c|}{ Symptom control reported by PCPs } \\
\hline & & $\begin{array}{l}\text { Very poorly } \\
\text { controlled } \\
(n=8)\end{array}$ & $\begin{array}{l}\text { Quite poorly } \\
\text { controlled } \\
(n=69)\end{array}$ & $\begin{array}{c}\text { Quite well } \\
\text { controlled } \\
(n=371)\end{array}$ & $\begin{array}{c}\text { Very well } \\
\text { controlled } \\
(n=116)\end{array}$ \\
\hline Oral antihistamines & $66 \%$ & $63 \%$ & $59 \%$ & $72 \%$ & $69 \%$ \\
\hline Intranasal glucocorticosteroids & $44 \%$ & $75 \%$ & $43 \%$ & $46 \%$ & $49 \%$ \\
\hline Environmental control & $29 \%$ & $63 \%$ & $41 \%$ & $32 \%$ & $20 \%$ \\
\hline Intranasal decongenstants & $26 \%$ & $63 \%$ & $45 \%$ & $27 \%$ & $16 \%$ \\
\hline Oral decongestants & $19 \%$ & $63 \%$ & $25 \%$ & $21 \%$ & $12 \%$ \\
\hline Intranasal H1-antihistamines & $14 \%$ & $25 \%$ & $14 \%$ & $16 \%$ & $9 \%$ \\
\hline Asthma treatments & $13 \%$ & $25 \%$ & $19 \%$ & $13 \%$ & $13 \%$ \\
\hline Intraocular antihistamine & $12 \%$ & $13 \%$ & $13 \%$ & $14 \%$ & $9 \%$ \\
\hline Oral glucocorticosteroids & $8 \%$ & $13 \%$ & $6 \%$ & $9 \%$ & $8 \%$ \\
\hline Intraocular chromone & $6 \%$ & $13 \%$ & $9 \%$ & $6 \%$ & $4 \%$ \\
\hline Immunotherapy (referral) & $5 \%$ & $25 \%$ & $4 \%$ & $4 \%$ & $6 \%$ \\
\hline None of the above & $6 \%$ & $\mathrm{~N} / \mathrm{A}$ & $\mathrm{N} / \mathrm{A}$ & $\mathrm{N} / \mathrm{A}$ & $\mathrm{N} / \mathrm{A}$ \\
\hline
\end{tabular}




\begin{tabular}{|c|c|c|c|c|}
\hline \multirow[b]{2}{*}{ Task } & \multicolumn{4}{|c|}{$\begin{array}{l}\text { Percentage of PCPs reporting effect } \\
\text { of AR on ability to perform daily } \\
\text { tasks }(n=600)\end{array}$} \\
\hline & No effect & $\begin{array}{c}\text { Limited } \\
\text { effect }\end{array}$ & $\begin{array}{c}\text { Moderate } \\
\text { effect }\end{array}$ & $\begin{array}{c}\text { Considerable } \\
\text { effect }\end{array}$ \\
\hline Concentration & $32 \%$ & $37 \%$ & $23 \%$ & $8 \%$ \\
\hline $\begin{array}{l}\text { Number of } \\
\text { patients seen }\end{array}$ & $59 \%$ & $26 \%$ & $12 \%$ & $4 \%$ \\
\hline Time with patient & $50 \%$ & $33 \%$ & $14 \%$ & $4 \%$ \\
\hline $\begin{array}{l}\text { Level of physical } \\
\text { contact with } \\
\text { patient }\end{array}$ & $42 \%$ & $36 \%$ & $16 \%$ & $6 \%$ \\
\hline Stress & $39 \%$ & $31 \%$ & $22 \%$ & $9 \%$ \\
\hline Mood & $33 \%$ & $39 \%$ & $21 \%$ & $7 \%$ \\
\hline
\end{tabular}

nasal symptoms alone, the presence of both ocular and nasal symptoms was also significantly associated with time missed from work ( $23 \%$ versus $31 \% ; p=0.031$ ).

Ability to perform daily tasks was affected most by runny or blocked nose and itchy red eyes. PCPs reported that their AR symptoms moderately or considerably affected their concentration $(31 \%)$, stress level $(31 \%)$, general mood when dealing with patients $(28 \%)$, level of physical contact with patients (22\%), time spent with each patient (18\%), and the number of patients that they saw (16\%) (see Table 4).

\section{Influence of personal experience of AR on PCPs' management of patients with AR}

The mean prevalence of AR patients in the $\mathrm{PCPS}^{\prime}$ practice populations was $16.5 \%$ (two-thirds (64\%) with intermittent $A R$ and $34 \%$ with persistent $A R$ ), though there was a wide variation in the reported prevalence. PCPs with AR reported a slightly (but significantly) higher mean proportion of $A R$ patients in their practice compared with those PCPs not suffering from $A R(17.7 \%$ and $15.3 \%$ respectively; $p=0.015)$. Results were broadly similar between countries although PCPS from Brazil did report a higher proportion of patients suffering from persistent AR $(40 \%)$ compared to the other countries (30-35\%).

Awareness of the full ARIA guidelines was not significantly affected by the PCPs' AR status or symptom type, with $41 \%$ being unaware of the guidelines and $29 \%$ stating that they preferred to treat patients' individual needs irrespective of the guidelines. PCPs from Australia (46.9\%), Canada (44.7\%), France $(40.7 \%)$ and the UK $(49.3 \%)$ were significantly more likely to be unaware of the ARIA guidelines when compared with the other countries. Only $3 \%$ of all PCPs followed the guidelines for all AR patients, with a further $27 \%$ basing their management on the ARIA guidelines but adapting them
Table 5a. Importance to PCPs (with and without AR) of patient-relevant factors of AR treatment (a low er score indicates a higher level of importance). See Table $5 \mathbf{b}$ (Appendix B, available at www.thepcrj.org) for a detailed breakdown of the PCP responses to each of the eight patient-relevant factors.

\begin{tabular}{lccc} 
& \multicolumn{3}{c}{ Importance to PCPs of } \\
& \multicolumn{2}{c}{ patient-relevant factors } \\
\hline $\begin{array}{l}\text { Patient-relevant factors } \\
\text { of treatment }\end{array}$ & $\begin{array}{c}\text { Total } \\
(n=1201)\end{array}$ & $\begin{array}{c}\text { AR sufferer } \\
(n=600)\end{array}$ & $\begin{array}{c}\text { Non AR } \\
\text { sufferer } \\
(n=601)\end{array}$ \\
\hline
\end{tabular}

1. Improving patient $\begin{array}{llll}\text { quality of life } & 2.1 & 2.2 & 2.0\end{array}$

2. Providing a treatment most likely to result in high patient compliance

3. Preventing the onset of or development of comorbidities of AR

4. Patient emotional well-being

5. Providing affordable treatment for patients

6. Demands on patients from their professional lives 5.3

7. Demands on patients from their personal lives 5.5

8. Patient requests for specific treatment

according to the individual patient. Younger PCPs were significantly more likely to be unaware of the guidelines ( $48 \%$ aged $25-44$ years versus $37 \%$ aged $45-65$ years; $p=0.0002$ ).

The results of the questionnaire indicated that the relative importance given by PCPs to patient-relevant factors of AR treatment was similar between PCPs with and without AR; for example, improvement in their AR patients' overall quality of life was the most important patient-relevant factor to all physicians (see Table 5a). However, some significant differences were highlighted; compared to PCPs without AR, those with the disease gave a significantly higher ranking to patients' requests for a specific treatment $(p=0.011)$ and emotional well-being $(p=0.008)$, and gave a significantly lower ranking to preventing the onset or development of comorbidities $(p<0.0001)$ and providing a treatment most likely to result in high patient compliance $(p=0.005)$. Further data is given in Table $5 b$, available as Appendix $B$ at www.thepcrj.org, which gives a detailed breakdown of the 
Table 6. Importance to PCPs (with and without AR) of AR treatment attributes (the low er score indicates the higher level of importance).

\begin{tabular}{lccc} 
& \multicolumn{3}{c}{$\begin{array}{c}\text { Importance to PCPs of treatment } \\
\text { attributes }\end{array}$} \\
\hline Treatment attributes & $\begin{array}{c}\text { Total } \\
(n=1201)\end{array}$ & $\begin{array}{c}\text { AR sufferer } \\
(n=600)\end{array}$ & $\begin{array}{c}\text { Non AR } \\
\text { sufferer } \\
(n=601)\end{array}$ \\
\hline Reduction of symptom severity & 2.6 & 2.7 & 2.6 \\
Safety /side effects & 3.5 & 3.6 & 3.5 \\
$\begin{array}{l}\text { Speed of onset of action } \\
\text { Experience of PCP with the }\end{array}$ & 4.0 & 4.1 & 4.0 \\
treatment & 4.7 & 4.6 & 4.7 \\
Ease of administration & 4.8 & 4.8 & 4.9 \\
Duration of action & 5.0 & 4.9 & 5.0 \\
Guideline recommendation & 6.0 & 6.0 & 6.0 \\
$\begin{array}{l}\text { Treatment cost to practice or } \\
\text { state health service }\end{array}$ & 7.0 & 6.8 & 7.1 \\
Formulary recommendation & 7.3 & 7.4 & 7.3
\end{tabular}

$\mathrm{PCP}$ responses to each of the eight patient-relevant factors assessed.

When considering treatment attributes the two groups were also similar. Safety and effectiveness were the most important treatment attributes for all PCPs. Specific differences were again identified. For example, PCPs with AR ranked treatment costs to their practice slightly (but significantly) higher than PCPs without AR $(p=0.012)$ (see Table 6) although the cost of treatment did not rank highly when compared to some other treatment attributes for both PCPs suffering with AR and those without the disease.

When using monotherapy to treat mild AR, all PCPs were most likely to recommend or prescribe oral antihistamines as their first-choice treatment. PCPS without AR, how ever, were significantly more likely to recommend environmental control measures ( $53 \%$ versus $38 \%$ of PCPs with AR; $p<0.0001$ ), an intranasal antihistamine ( $29 \%$ versus $19 \% ; p=0.0001)$, and an intranasal decongestant ( $28 \%$ versus $22 \% ; p=0.010$ ). There was no difference between PCPs with and without AR in their first choice monotherapy for severe $A R$, which was equally likely to be an oral antihistamine $(54 \%)$ or an intranasal glucocorticoid (52\%). Compared to PCPs with AR, PCPs without the disease were significantly more likely to recommend an intranasal glucocorticoid (55\% versus $48 \%$; $p=0.009)$, an intranasal decongestant $(23 \%$ versus $17 \%$; $p=0.003)$ and environmental control measures $(33 \%$ versus $27 \% ; p=0.001$ ).

There was no difference between PCPs with and without $A R$ in their choice of combination therapy for either mild or severe AR. Significantly fewer PCPs would prescribe or recommend combination therapy for mild $A R$ than for moderate-severe AR $(93 \%$ versus $99 \% ; p<0.0001)$. PCPs using combination therapy for mild AR suggested over 300 different combinations, but the most frequent choice (by $15 \%$ of PCPs; $n=177$ ) was an oral antihistamine plus an intranasal glucocorticoid. PCPs chose over 450 different combinations for severe $A R$, but again the most frequent combination (recommended or prescribed by $9 \%$ of PCPs; $\mathrm{n}=112$ ) was an oral antihistamine plus an intranasal glucocorticoid.

\section{Discussion}

\section{Effects of AR on PCPs' w orking lives}

This is the first study to examine the impact of AR on the lives of PCPs. It shows that AR is associated with lost productivity, work absenteeism and 'presenteeism' (being present at work, but not fully functioning), similar to AR sufferers in the general population ${ }^{5-9}$ Over one-quarter of PCPs with AR reported losing an average of six hours of work a week during a typical week of AR symptoms. Yet those who did not miss work also reported detrimental effects on their professional effectiveness during their contact with patients. The study indicates an association between AR symptoms, symptom control and lost productivity, and that effective control of $A R$ symptoms significantly reduced the likelihood of absence from work. There was a significant association between selfemployment status for PCPs and continuing presence at work, although this was not influenced by AR symptom severity. This reflects research in the general European population demonstrating relatively low rates of absenteeism among self-employed sole traders and small employers despite their higher rates of stress and fatigue compared to employed individuals. ${ }^{11}$ Self-employment status was, however, less influential than AR symptom control, and so the burden of AR symptoms appears to be a more important contributor to absenteeism among PCPs in our study.

\section{Influence of PCPs' personal experience of AR on their management of AR patients}

This is the first study to show that personal experience of $A R$ influences PCPs' management of patients with the disease. All PCPs aim to provide the most effective treatment for their patients, but those with $A R$ assigned a higher ranking to patients' requests for a specific treatment and their emotional well-being. It was therefore surprising that, when choosing a specific treatment, PCPs with AR appeared to be more influenced than their colleagues without AR by costs to the practice or state health service. Although significant, the difference between the two groups was, however, small, and cost was a relatively minor consideration compared to the main influences of effectiveness and safety.

The results also suggest that personal experience of $A R$ 
may improve a PCP's ability to recognise the disease amongst their patients, since the AR patient population was slightly, but significantly, higher for PCPs with AR compared to those without AR. It remains unclear whether this was due to PCPs' greater awareness of the disease and superior diagnostic abilities, or because AR patients were more likely to consult them because they could provide better treatment. PCPs with AR were significantly less likely than PCPs without the disease to recommend an intranasal antihistamine, an intranasal decongestant or environmental control measures, possibly because of their personal experience of the lower effectiveness of these two classes of drug. Further explanations could be the cost implications of these therapies or that environment control measures can be complicated, time-consuming, costly, and not always practical to incorporate into everyday life.

In contrast, personal experience of AR did not influence PCPs' most frequent first choice of monotherapy or combination therapy in either mild or moderate-severe AR. Similarly, there is no indication that PCPs with AR are more likely to incorporate current evidence-based guidelines into their clinical practice when treating either themselves or their AR patients, with younger physicians being the least likely. Indeed, it is remarkable that PCPs with AR were less likely than PCPs without AR to recommend an intranasal glucocorticoid, the most effective treatment for moderatesevere AR.

Some PCPs may have been following the ARIA guidelines without being aware of the fact, since the guidelines' provisions have been included in national AR guidelines in some of the countries included in the study (UK, Canada, Italy, France and Germany). Furthermore, since the new ARIA classification is based on suspected pathophysiology rather than on clinical presentation (i.e. seasonal or perennial AR), PCPs may have difficulty in implementing the guidelines in their everyday practice in primary care. Previous studies have also demonstrated suboptimal management of AR patients in primary care ${ }^{12,13}$ and PCPs' lack of awareness of, or adherence to, ARIA guidelines is confirmed in our study by their low ranking of guideline recommendations, their first line choice of treatment, and the hundreds of reported therapy combinations.

\section{Limitations of the study}

The mean AR prevalence of $16.5 \%$ reported in our study reflects findings in other primary care populations, ${ }^{14}$ but our findings have limitations since our definitions of persistent $A R$ and intermittent AR did not precisely reflect those of the ARIA guidelines.

The study population was drawn from a panel of healthcare professionals, with no special interest in $A R$, who were willing to be involved in research. This method (rather

\section{Discussion summary}

This is the first study demonstrating the impact of $A R$ on PCPs showing association with lost productivity, absenteeism and reduction in professional performance. Personal experience of AR significantly influences PCPs' management of $A R$ and may improve their AR diagnostic ability. All PCPs aim to provide the most effective treatment, but those with $A R$ assigned a higher ranking to patients' requests for a specific treatment and their emotional well-being. Personal experience of AR did not influence PCPs' most frequent first choice of monotherapy or combination therapy. Possible limitations of this study were that the definitions of persistent and intermittent AR did not precisely reflect those of the ARIA guidelines, and also that the study population was drawn from a panel of health care professionals willing to be involved in research rather than from the general population of PCPs.

than approaching the general population of healthcare professionals) was employed in order to obtain the large study population required by the study and to provide the wide geographical spread of countries.

The balance between persistent $A R$ and intermittent $A R$ in our study is equivalent to that in the general population, $, 1,15$ but the preponderance of male PCPs $(73 \%$ versus $27 \%$ female) does not reflect the epidemiology of $A R$, and is greater than the mean of $62 \%$ amongst PCPs in the countries included in the study (data unavailable in Brazil). ${ }^{16}$ In the general population, women are absent from work more often than men in similar employment, ${ }^{17}$ but since gender was not included in the eligibility criteria for our study it is not possible to conclude that gender imbalance led us to underestimate AR-related absenteeism among the PCPs in our study.

Furthermore, some subsets of the total large study population - for example AR sufferers whose symptoms were poorly controlled - were very small, resulting in a low sample base for that group of PCPS.

\section{Recommendations}

By selecting eight countries, the current study has been able to focus on global findings. Future analysis of our study data will focus on a comparison of the influence of persistent $A R$ and intermittent $A R$, and, whilst the majority of data are consistent between countries, we plan to undertake a detailed analysis of international differences, including the influence of healthcare systems, reimbursement arrangements, and referral practices. In order to enable more detailed investigation of the influence of $A R$ on PCPs' professional lives and their management of $A R$ patients, other investigators should ensure that definitions of persistent $A R$ and intermittent $A R$ precisely reflect ARIA criteria 
and that their study design enables measurement of the severity of AR symptoms. Qualitative research is also needed to resolve important questions highlighted by our study, including the reasons for PCPs' choice of treatment, the influence of personal experience of $A R$ symptoms on their management of their patients with $A R$, and their attitudes to the use of evidencebased guidelines when managing their own and their patients' AR.

Our study confirms that suboptimal treatment remains common in primary care, whether PCPs are managing their own or their patients' symptoms. Moreover, an unknown proportion of intermittent and persistent AR patients treat themselves with OTC medications. Management of AR by PCPs can be improved in clinical trials by adoption of the structured approach inherent in guidelines, ${ }^{18}$ but studies are needed to assess the long-term outcome and feasibility of these interventions in everyday clinical practice.

\section{Conflicts of interest}

None.

\section{Acknow ledgements}

The authors acknowledge the contribution of Sue Lyon and Stella Deane. The data were analysed by personnel employed by Healthcare Research Worldwide, an international market research company with a special interest in healthcare issues.

\section{Funding declaration}

The study was funded by GlaxoSmithKline R\&D Limited.

\section{References}

1. Bousquet J, Van Cauwenberge P, Khaltaev N, ARIA Workshop Group, World Health Organisation. AR and its impact on asthma. J Allergy Clin Immunol 2001;108(Suppl 5):S147-334. doi:10.1067/mai.2001.118891

2. Maurer $M$, Zuberbier T. Undertreatment of rhinitis symptoms in Europe: findings from a cross-sectional survey. Allergy 2007;62(9):1057-63. doi:10.1111/j.1398-9995.2007.01367.x

3. Gregory C, Cifaldi M, Tanner LA. Targeted intervention programs. Creating a customized practice model to improve treatment of allergic rhinitis in a managed care population. Am J Managed Care 1999;5(4):485-96.

4. Price D, Bond C, Bouchard J, et al. International Primary Care Respiratory Group (IPCRG) Guidelines: Management of allergic rhinitis. Prim Care Respir J
2006;15:58-70. doi:10.1016/j.pcri.2005.11.002

5. Burton WN, Conti DJ, Chen CY, Schultz $A B$, Edington DW. The impact of allergies and allergy treatment on worker productivity. J Occup Environ Med 2001;43(1):64-71. doi:10.1097/00043764-200101000-00013

6. Kessler RC, Almeida DM, Berglund P, Stang P. Pollen and mold exposure impairs the work performance of employees with allergic rhinitis. Ann Allergy Asthma Immunol 2001;87(4):289-95.

7. Lamb $\mathrm{CE}$, Ratner $\mathrm{PH}$, Johnson $\mathrm{CE}$, et al. Economic impact of workplace productivity losses due to allergic rhinitis compared with select medical conditions in the United States from an employer perspective. Curr Med Res Opin 2006;22(6):1203-10. doi:10.1185/030079906X112552

8. Shedden A. Impact of nasal congestion on the quality of life and work productivity in allergic rhinitis: findings from a large online survey. Treat Respir Med 2005;4(6):439-46. doi:10.2165/00151829-200504060-00007

9. Szeinbach SL, Seoane-Vasquez EC, Beyer A, Williams PB. The impact of rhinitis on work productivity. Prim Care Respir J 2007;16(2):98-105. doi:10.3132/ pcrj.2007.00015

10. Reilly MC, Zbrozek AS, Dukes EM. The validity and reproducibility of a work productivity and activity impairment instrument. Pharmacoeconomics 1993;4(5):353-65. doi:10.2165/00019053-199304050-00006

11. Benavides FG, Benach J, Diez-Roux, Roman C. How do types of employment relate to health indicators? Findings from the Second European Survey on Working Conditions. J Epidemiol Community Health 2000;54(7):494-501. doi:10.1136/jech.54.7.494

12. Ryan D, Grant-Casey J, Scadding G, Pereira S, Pinnock H, Sheikh A. Management of allergic rhinitis in UK primary care: baseline audit. Prim Care Respir J 2005;14(4):204-9. doi:10.1016/j.pcrj.2005.03.009

13. Scadding GK, Richards DH, Price MJ. Patient and physician perspectives on the impact and management of perennial and seasonal allergic rhinitis. Clin Otolaryngol Allied Sci 2000;25(6):551-7. doi:10.1046/j.13652273.2000.00417.x

14. Bachau V, Durham SR. Prevalence and rate of diagnosis of allergic rhinitis in Europe. Eur Respir J 2004;24(5):758-64. doi:10.1183/09031936.04.00013904

15. Bauchau V, Durham SR. Epidemiological characterization of the intermittent and persistent types of allergic rhinitis. Allergy 2005;60(3):350-3. doi:10.1111/j.1398-9995.2005.00751.x

16. European Pharmaceutical Market Research Association - Doctor Universe Statistics In Major Markets. http://www.ephmra.org/PDF/Dr\%20 Universereportpdf19December03.pdf

17. Mastekaasa A, Olsen KM. Gender, absenteeism and job characteristics. Work Occupation 1998;25(2):195-228. doi:10.1177/0730888498025002004

18. Bousquet J, Lund VH, van Cauwenberge $P$, et al. Implementation of guidelines for seasonal allergic rhinitis: a randomised controlled trial. Allergy 2003;58(8):733-41. doi:10.1034/j.1398-9995.2003.00076.x 
Appendix A. Primary Care Physicians' Study Online Questionnaire

All PCPs answered questions 1-8 and 16-21, while questions 10-15 were answered only by PCPs with AR.

\section{Section 1: Respondent profile (all respondents)}

1. Which, if any, of the following areas have you participated in any market research on within the past 3 months?
Asthma
Allergies
Acid-peptic disorders and treatments
Emollients and antipruritics
$\square$ Diabetes
$\square$ Oncology

2. Are you male / female?

3. What is your age?

4. How many years have you been practising as a primary care practitioner?

5. What is your current working status? Please check as many boxes as are applicable to you
Full-time
Part-time
$\square$ Retired
Self-employed
Other

6. How many hours do you normally work in a week?

7. How many other primary care practitioners are there in the practice in which you work?

8. Approximately, how many patients do you have on your personal list?

\section{Section 2: PCP AR sufferers (all respondents)}

9. We would now like to ask you about your own experience of any of the following symptoms.

Which, if any, of the following do you suffer from?

Intermittent allergic rhinitis (IAR)

Persistent allergic rhinitis (PAR)

Both IAR and PAR

None of the above

10. Thinking about allergic rhinitis (AR), which, if any, of the following do you suffer from when not taking AR medication?

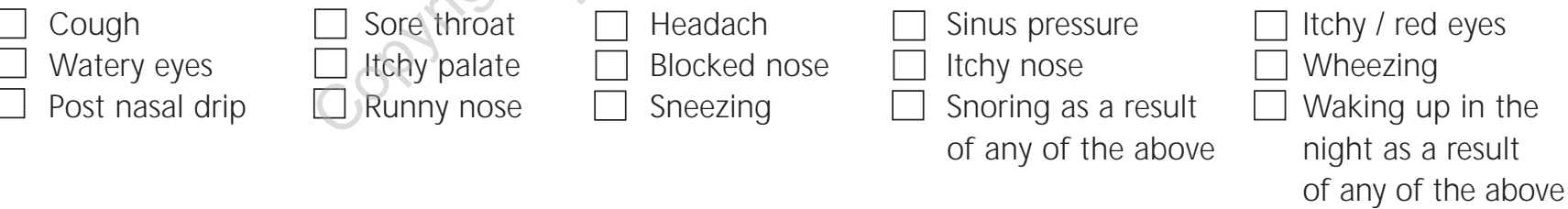

11. For each of the symptoms you've mentioned, please rank this in order of the degree of impact they have on your ability to perform your daily tasks, where 1 means this symptom has the most impact.
$\square$ Cough
Sore throat
Watery eyes
Itchy palate
$\square$ Headach
Itchy nose
Snoring
$\square$ Sinus pressure
Blocked nose
Runny nose
Sneezing
$\square$ Itchy / red eyes
Wheezing
Waking up in the night

12. Which, if any, of the following do you use to treat these symptoms that you experience?

Oral antihistamine

$\square \quad$ Oral decongestant
$\square \quad$ Intranasal decongestant
$\square \quad$ Intraocular chromone

$\square$ Oral glucocorticosteroid

Intranasal H1-antihistamine

Intraocular antihistamine

Referral for diagnostics/ possible immunotherapy

Environmental control measures e.g. lifestyle changes 
P Van Cauwenberge et al.

Appendix A. Primary Care Physicians' Study Online Questionnaire

13. How well do you feel your symptoms are controlled with this medication?

Not at all well controlled $\quad \square$ Not very well controlled

Quite well controlled $\quad \square$ Very well controlled

\section{Section 3: Impact on w ork for PCP AR sufferers (AR sufferers only)}

14. For this next question, please think about a week when you typically encounter the symptoms you have described experiencing yourself.

During this week, how many hours did you miss from work because of these problems typically associated with these symptoms? Please include hours you missed on sick days, times you went in late, left early etc. because of these symptoms.

Hours missed in a week because of these typical symptoms

15.a-f To what extent do these symptoms affect you in the following ways?

\begin{tabular}{|l|l|l|l|l|}
\hline $15 a$ My concentration at work & $\begin{array}{l}\text { My symptoms } \\
\text { affect me } \\
\text { considerably }\end{array}$ & $\begin{array}{l}\text { My symptoms } \\
\text { affect me } \\
\text { moderately }\end{array}$ & $\begin{array}{l}\text { My symptoms } \\
\text { affect me to } \\
\text { a limited extent }\end{array}$ & $\begin{array}{l}\text { My symptoms } \\
\text { do not affect } \\
\text { me at all }\end{array}$ \\
\hline $15 b$ The number of patients I see & & & & \\
\hline $\begin{array}{l}15 c \quad \text { The time I spend with each } \\
\text { patient }\end{array}$ & & & & \\
\hline $\begin{array}{l}15 d \quad \text { My level of physical patient } \\
\text { contact (e.g. touching, handling) }\end{array}$ & & & & \\
\hline 15 e My stress level at work & & & & \\
\hline $\begin{array}{l}15 f \quad \text { My general mood when dealing } \\
\text { with patients }\end{array}$ & & & & \\
\hline
\end{tabular}

\section{Section 4: Impact on patient management (all respondents)}

16a. Of all your patients, approximately what percentage has any form of allergic rhinitis?

16b. And of all your patients with allergic rhinitis, what percentage has intermittent allergic rhinitis (IAR) and what percentage of patients have persistent allergic rhinitis (PAR)?

Percentage of patients with intermittent allergic rhinitis (IAR)

Percentage of patients with persistent allergic rhinitis (PAR)

17. To what extent do you follow the ARIA-guidelines in the treatment of allergic rhinitis?

I follow them for all AR patients

I base the management my AR patients on these guidelines and I adapt according to the individual situation

I prefer not to treat patients' individual needs irrespective of the ARIA-guidelines

I am not aware of the ARIA-guidelines 
Appendix A. Primary Care Physicians' Study Online Questionnaire

18. Please rank the following factors in order of importance to you, where 1 is the most important to you and 8 is the least important to you

$\square$ Improving patients' overall quality of life

$\square$ Preventing the onset or development of comorbidities of allergic rhinitis (AR) e.g. asthma

Providing a treatment that is most I likely to result in high patient compliance

$\square$ Patient requests for specific treatment

Providing affordable treatments for patients

Demand on patients' personal lives e.g. family commitments

Demands on patients' professional lives

Patients' emotional well-being

19a. Which of the following treatments, if any, would you prescribe or recommend as a monotherapy for a patient with mild AR?

Please indicate any treatments you would prescribe or recommend as stand alone treatment for mild AR.

$\square$
$\square$
$\square$
$\square$
$\square$
$\square$
$\square$
$\square$
$\square$

Environmental control measures e.g. lifestyle changes

Oral decongestant

Intranasal H1-antihistamine

Intranasal glucocorticosteroid

Oral antihistamine

$\square$ Oral glucocorticosteroid

$\square$ Intranasal decongestant

Intraocular chromone

Intramuscular corticosteroid treatment

Intraocular steroid

I would not recommend any stand-alone treatment for a patient with mild AR

I would not recommend any treatment for a patient with mild AR

19b. Which of the following treatments, if any, would you prescribe or recommend as a combination therapy for a patient with mild AR?

Please indicate which 2 or more treatments that you would typically prescribe or recommend in combination for a patient with mild AR.

Environmental control measures e.g. lifestyle changes

Oral decongestant

Intranasal H1-antihistamine

Intranasal glucocorticosteroid

Intraocular chromone

Intramuscular corticosteroid treatment

Intraocular steroid

I would not recommend any combination treatment for a patient with mild AR
Oral antihistamine

Oral glucocorticosteroid

$\square$ Intranasal decongestant

$\square$ Intraocular antihistamine

$\square$ (Referral for) immunotherapy

$\square$ Intraocular decongestant

20a. Which of the following treatments, if any, would you prescribe or recommend as a monotherapy for a patient with moderate to severe AR?

Please indicate any treatments you would prescribe or recommend as stand alone treatment for moderate to severe AR.

Environmental control measures e.g. lifestyle changes

Oral decongestant

Intranasal H1-antihistamine

Intranasal glucocorticosteroid

Intraocular chromone
Oral antihistamine

Oral glucocorticosteroid

Intranasal decongestant

Intraocular antihistamine

(Referral for) immunotherapy 
P Van Cauwenberge et al.

Appendix A. Primary Care Physicians' Study Online Questionnaire

$\square$ Intramuscular corticosteroid treatment

Intraocular decongestant

Intraocular steroid

I would not recommend any stand-alone treatment for a patient with moderate to severe AR

I would not recommend any treatment for a patient with moderate to severe AR

$20 \mathrm{~b}$ Which of the following treatments, if any, would you prescribe or recommend as a combination therapy for a patient moderate to severe AR?

Please indicate which 2 or more treatments that you would typically prescribe or recommend in combination for a patient with moderate to severe AR.

Environmental control measures e.g. lifestyle changes

Oral decongestant

Intranasal H1-antihistamine

Intranasal glucocorticosteroid

Intraocular chromone

Intramuscular corticosteroid treatment

Intraocular steroid

I would not recommend any combination treatment for a patient with moderate to severe AR

21. Please rank the following treatment attributes in order of importance to you when considering treatment options for patients suffering from allergic rhinitis.

1 means this treatment attribute is most important to you and 9 means this treatment attribute is least important to you.

Reduction of symptom severity

Duration of action

Speed of onset of action

Safety / side effects

Ease of administration

Treatment cost to your practice or state health service

Your experience with the treatment

Guideline recommendation

Formulary recommendation 
Appendix B Figure 5b. Detailed PCP responses to the eight patient-relevant factors shown in Table 5a.

All PCPs answered questions 1-8 and 16-21, while questions 10-15 were answered only by PCPs with AR.

\begin{tabular}{|ll|}
\hline 1. Improving patient quality of life \\
\hline Most important to you (1.0) & $18 \%$ \\
\hline $2(2.0)$ & $23 \%$ \\
\hline $3(3.0)$ & $17 \%$ \\
\hline $4(4.0)$ & $12 \%$ \\
\hline $5(5.0)$ & $10 \%$ \\
\hline $6(6.0)$ & $9 \%$ \\
\hline $7(7.0)$ & $6 \%$ \\
\hline Least important to you (8.0) & $6 \%$ \\
\hline
\end{tabular}

\begin{tabular}{|ll|}
\hline $\begin{array}{l}\text { 5. Providing affordable treatment for } \\
\text { patients }\end{array}$ \\
\hline M ost important to you (1.0) & $4 \%$ \\
\hline $2(2.0)$ & $9 \%$ \\
\hline $3(3.0)$ & $12 \%$ \\
\hline $4(4.0)$ & $15 \%$ \\
\hline $5(5.0)$ & $14 \%$ \\
\hline $6(6.0)$ & $11 \%$ \\
\hline $7(7.0)$ & $15 \%$ \\
\hline Least important to you (8.0) & $19 \%$ \\
\hline
\end{tabular}

\begin{tabular}{|ll|}
\hline $\begin{array}{l}\text { 2. Providing a treatment most likely } \\
\text { to result in high patient compliance }\end{array}$ \\
\hline Most important to you (1.0) & $11 \%$ \\
\hline $2(2.0)$ & $24 \%$ \\
\hline $3(3.0)$ & $25 \%$ \\
\hline $4(4.0)$ & $14 \%$ \\
\hline $5(5.0)$ & $8 \%$ \\
\hline $6(6.0)$ & $7 \%$ \\
\hline $7(7.0)$ & $6 \%$ \\
\hline Least important to you (8.0) & $3 \%$ \\
\hline
\end{tabular}

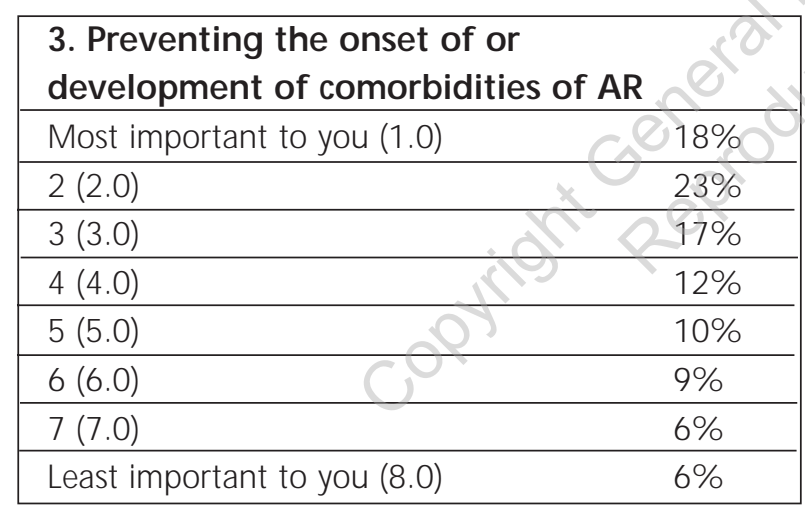

\begin{tabular}{|ll|}
\hline $\begin{array}{l}\text { 6. Demands on patients from their } \\
\text { professional lives }\end{array}$ \\
\hline M ost important to you (1.0) & $2 \%$ \\
\hline $2(2.0)$ & $5 \%$ \\
\hline $3(3.0)$ & $11 \%$ \\
\hline $4(4.0)$ & $16 \%$ \\
\hline $5(5.0)$ & $16 \%$ \\
\hline $6(6.0)$ & $20 \%$ \\
\hline $7(7.0)$ & $18 \%$ \\
\hline Least important to you (8.0) & $12 \%$ \\
\hline
\end{tabular}

\begin{tabular}{|ll|}
\hline $\begin{array}{l}\text { 7. Demands on patients from their } \\
\text { personal lives }\end{array}$ \\
\hline M ost important to you (1.0) & $2 \%$ \\
\hline $2(2.0)$ & $5 \%$ \\
\hline $3(3.0)$ & $7 \%$ \\
\hline $4(4.0)$ & $13 \%$ \\
\hline $5(5.0)$ & $17 \%$ \\
\hline $6(6.0)$ & $21 \%$ \\
\hline $7(7.0)$ & $21 \%$ \\
\hline Least important to you (8.0) & $13 \%$ \\
\hline
\end{tabular}

\begin{tabular}{|ll|}
\hline 4. Patient emotional well-being \\
\hline Most important to you (1.0) & $3 \%$ \\
\hline $2(2.0)$ & $11 \%$ \\
\hline $3(3.0)$ & $12 \%$ \\
\hline $4(4.0)$ & $14 \%$ \\
\hline $5(5.0)$ & $18 \%$ \\
\hline $6(6.0)$ & $17 \%$ \\
\hline $7(7.0)$ & $14 \%$ \\
\hline Least important to you (8.0) & $11 \%$ \\
\hline
\end{tabular}

\begin{tabular}{|ll|}
\hline \multicolumn{2}{|l|}{ 8. Patient requests for specific treatment } \\
\hline M ost important to you (1.0) & $3 \%$ \\
\hline $2(2.0)$ & $5 \%$ \\
\hline $3(3.0)$ & $7 \%$ \\
\hline $4(4.0)$ & $9 \%$ \\
\hline $5(5.0)$ & $13 \%$ \\
\hline $6(6.0)$ & $12 \%$ \\
\hline $7(7.0)$ & $18 \%$ \\
\hline Least important to you (8.0) & $33 \%$ \\
\hline M ean score : & 5.9 \\
\hline
\end{tabular}

